\title{
Joint production and quality control of unreliable batch manufacturing systems with rectifying inspection
}

\author{
Bassem Bouslah $^{\mathrm{a}}$, Ali Gharbib ${ }^{\mathrm{b} *}$ and Robert Pellerin ${ }^{\mathrm{a}}$ \\ a Department of Mathematics and Industrial Engineering, École Polytechnique de Montréal, Québec, \\ ${ }^{\mathrm{b}}$ Automated Production Engineering Department, Production System Design and Control Laboratory, \\ Ecole de technologie supérieure, University of Québec, Montreal (Québec), Canada
}

\begin{abstract}
Production control policy and economic sampling plan design problems have been studied separately in previous research. This paper considers a joint production control policy and economic single sampling plan design for an unreliable batch manufacturing system. The production is controlled by a modified hedging point policy which consists in building and maintaining a safety stock of finished product to avoid shortages during corrective maintenance. The main objective of this paper is to determine simultaneously the economic production quantity, the optimal safety stock level and the economic sampling plan design which minimize the expected overall cost. A stochastic mathematical model is developed and solved using a simulation optimization approach based on the response surface methodology. Simulation is used to imitate the complex dynamic and stochastic behaviour of processes as in the real-life industrial systems. The obtained results show clearly strong interactions between production quantity, inventory state and sampling plan design which confirm the necessity of jointly considering production and quality control parameters in an integrated model. Moreover, it is shown a significant impact of production system reliability on the economic sampling plan design and therefore on the quality of finished product delivered to consumers. Numerical example and sensitivity analyses are presented for illustrative purposes.
\end{abstract}

Keywords: Unreliable manufacturing system, sampling plan, economic production quantity, simulation, response surface methodology.

\section{Introduction}

In the literature, batch manufacturing systems are controlled using the economic production quantity (EPQ) model. The classical EPQ model has been widely extended by many researchers to control various real-life manufacturing situations such as production equipment failures and quality imperfection. The impact of stochastic machine breakdowns and corrective maintenance on the economic batch size and the optimal safety stock decisions has been investigated in the pioneered works of Groenevelt et al. (1992a, 1992b) which provided a framework for many extensions of EPQ model to unreliable production systems as in Kim et al. (1997) and Chung (2003). On the other hand, Porteus (1986) and Rosenblatt and Lee (1986) were the first who studied the effect of quality imperfection on the EPQ model. In both studies, the researchers assumed that the deterioration of production system is a random process 
characterized by two states: 'in-control' state when all items produced are conforming of quality and 'out-of-control' state when some percentage of items produced are defectives. Lee and Rosenblatt (1987) incorporated maintenance by inspection feature into EPQ model to monitor the production process deterioration. They focused on simultaneously determining of the optimal batch size and the optimal inspection schedule. Many subsequent extensions have been undertaken based on Rosenblatt and Lee's models such as in Kim and Hong (1999) and Chung and Hou (2003). In recent years, the joint production system breakdowns and process quality deterioration problems have been investigated in EPQ model by Chiu et al. (2007), Liao et al. (2009), Chakraborty et al. (2009) and Sana and Chaudhuri (2010).

In most existing EPQ models, the researchers did not specify how the product-quality control is performed. Most of them used inspection schedules to mainly control the production process deterioration and not to consistently control the quality of product. In addition, they did not indicate how the nonconforming items produced between two successive inspections can be discovered and treated. Also, many authors assumed that the inspection is made instantly during batch processing and the inspection delay is negligible. However, inspection is in itself an important part of quality assurance that should be fairly represented in EPQ model. In real-life manufacturing organisations, it is recommended to use statistical quality control techniques, such as control charts or acceptance sampling plans, especially when the cost of $100 \%$ inspection is higher than the cost of delivering a certain proportion of nonconforming items (Besterfield, 2009). Only few researchers have integrated statistical quality control techniques into EPQ models such as Rahim and Ben-Daya (1998) who presented an integrated model for a continuous production process for joint economic determination of production quantity, inspection schedule and $\bar{x}$-control chart design.

To the author's knowledge, quality control using lot-by-lot single acceptance sampling plan by attributes has not been investigated in the production context, although extensive research in its different aspects and properties has been carried out (Wetherill and Chiu, 1975). In fact, one can find several researches which have attempted to design economically the single sampling plan but without considering production and system reliability factors. Among these, Ercan et al. (1974) developed a mathematical model to derive minimum cost single acceptance sampling plans by attribute recognizing the interrelations among average incoming quality limit, process quality level and average outgoing quality limit. Moskowitz and Berry (1976) presented a Bayesian algorithm for determining optimal single acceptance plan parameter values when discrete distributions are used to measure product quality, and when the sampling cost is either a linear or strictly convex function. Moreover, Moskowitz et al. (1979) developed a two-stage optimization algorithm for determining the optimal economic single sample acceptance plan when the prior distribution of lot quality and the sampling distribution are discrete. The proposed algorithm gives a minimal improvement in solution quality compared to the Bayesian algorithm, but the minimum cost plan is obtained much faster. Ravindran et al. (1986) presented two nonlinear integer goal programming models (with a constant/prior probability distribution of the 
lot fraction defective) for the determination of optimal acceptance sampling plan which explicitly considered the two conflicting criteria of average lot inspection cost and average outgoing quality. Much later, Ferrell and Chhoker (2002) developed mathematical models that can be used to design both $100 \%$ inspection and single sampling plans, with and without inspector error when a Taguchi-like loss function is used to describe the cost associated with any deviation between the actual value of a product's quality characteristic and its target value. The above models, which are mainly designed to control received commodity from suppliers, are commonly developed to minimize an expected total cost including inspection, batches acceptance and rejection costs. Finally, economic single acceptance sampling plan have been integrated with economic ordering quantity (EOQ) model by Peters et al. (1988), BenDaya et al. (2006) and Ben-Daya and Noman (2008).

In this paper, we propose a joint economic production and quality control design model for unreliable manufacturing systems, which has the following three features: the production is controlled by a modified hedging point policy (HPP), the quality control is performed by a single acceptance sampling by attributes, and the batch sizing, the hedging level and the sample size are decision variables. Our choice to use the HPP for the production-inventory control is motivated by its flexibility, feedback and optimality properties ((Bielecki and Kumar, 1988), (Bouslah et al., 2012)). The single sampling plan by attributes is the most commonly applied sampling procedure in industry because of its simplicity compared to double, multiple and sequential sampling (Wetherill and Chiu, 1975). The problem is formulated as a stochastic mathematical model considering all production and quality control tasks with non-negligible processing delays. Given that the proposed optimization problem is complex and no analytical solution is available, we developed a simulation model to imitate the real dynamic and stochastic behaviour of the manufacturing system. Then, we used simulation with optimization techniques (design of experiments and response surface methodology) to jointly optimize production and quality decision variables which minimize the total incurred cost including quality control costs, holding and backlog costs and transportation cost of batches produced.

The remainder of this paper is organized as follows. Section 2 presents the notation. Section 3 describes the problem under study. The optimization problem formulation is presented in section 4. Section 5 explains the resolution approach. An illustrative numerical example of the resolution approach with a thorough sensitivity analysis is given in section 6. Finally, section 7 concludes this paper.

\section{Notation}

The following are the notations used in this paper:

$q(t) \quad$ Batch-in-process level at time $t$ (units)

$x(\mathrm{t}) \quad$ Inventory level at time $t$

$y(\mathrm{t}) \quad$ Inventory position at time $t$

$u($.$) \quad Production rate (units/time)$ 
$u^{i} \quad$ Production rate of the $i$ th batch (units/time)

$u_{\max }$ Maximum production rate (units/time)

$d \quad$ Constant demand rate (units/time)

$p($.) Proportion of nonconforming items (random variable)

$p^{i} \quad$ Proportion of nonconforming items in the $i$ th batch (random variable)

$n \quad$ Sample size (decision variable)

$c$ Acceptance number on the second sample (decision variable)

$Q \quad$ Production batch size (units) (decision variable)

$Z \quad$ Hedging level of inventory position (decision variable)

$\theta_{i} \quad$ Production start time of the $i$ th batch

$\delta_{i} \quad$ Production end time of the $i$ th batch

$N_{\infty} \quad$ Long-term cumulative total number of batches produced

TTF Time To Failures (random variable)

TTR Time To Repair (random variable)

$\tau_{\text {insp }} \quad$ Inspection delay per unit (time/unit)

$\tau_{\text {rect }} \quad$ Rectification delay per unit (time/unit)

$C^{+} \quad$ Unit holding cost (\$/unit)

$C^{-} \quad$ Unit backlog cost (\$/unit)

$C_{t r} \quad$ Cost of batch transportation (\$/load)

$C_{\text {insp }} \quad$ Unit inspection cost (\$/unit)

$C_{\text {rect }}$ Unit rectification cost (\$/unit)

$C_{r e p} \quad$ Unit replacement cost (\$/unit)

\section{Problem description}

\subsection{Production system}

Consider an imperfect production system subject to stochastic breakdowns and repairs and supplying a downstream stock $x($.). The production system produces one single item in batches of size $Q$ in order to meet a constant and continuous demand $d$. The batch-in-process is stored in a downstream area of the system (as illustrated in Figure 1) until the production of the actual batch is completed. The system availability state can be described at each time $t$ by a stochastic process $\{\alpha(t)\}$ taking values in $\{0,1\}$. $\alpha(t)=1$, if the production system is available at time $t$, and, $\alpha(t)=0$, if not. When a failure occurs during the production cycle, the production of interrupted batches is always resumed after repair. Let $q(t)$ be a piecewise continuous variable which describes the batch processing progress at time $t$. Let $0 \leq q(t) \leq Q$ be the capacity constraint of the batch-in-process level. 


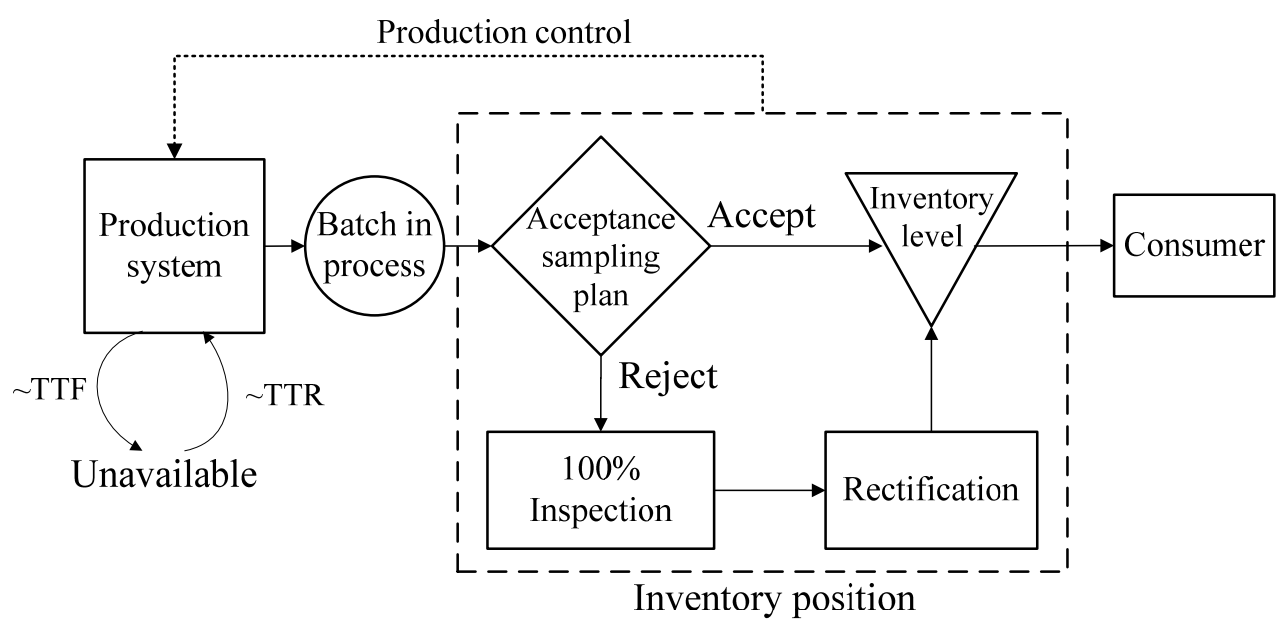

Figure 1. Unreliable and imperfect production system with quality control.

Because the production process is imperfect, a certain random proportion $p($. of nonconforming items is always produced. We assume that the proportion of nonconforming items $p($.) varies from batch to batch. As in Salameh and Jaber (2000), we consider that the number of nonconforming items in each $i$ th batch is equal to $p^{i} Q$ proportionally to the batch size $Q$, where $p^{i}$ is the proportion of nonconforming items in the $i$ th batch following a prior known probability distribution of $p($.$) . Once produced, a$ quality control is performed on the batch to decide whether it is acceptable or not.

\subsection{Quality control policy}

The quality control policy consists of a lot-by-lot single acceptance sampling plan with parameters $n$ and $c$. A sample of size $n$ is drawn randomly from the batch, and inspected item-by-item by attributes. The sample inspection duration is equal to $n \tau_{\text {insp }}$. If the number of nonconforming items in the sample does not exceed the acceptance number $c$ , the batch is accepted and the $k$ nonconforming items are replaced, from a stock of known good items, before the transport of the entire batch to the final stock area. Otherwise, the batch is rejected. We assume in our study that all inspection operations are performed with free error. Rejected batches are $100 \%$ inspected and all nonconforming items are sorted by inspection personnel. The duration of this operation is equal to $(Q-n) \tau_{i n s p}$. Then, the nonconforming items are rectified. The delay of rectification of the nonconforming items discovered in the $i$ th batch is equal to $p^{i} Q \tau_{\text {rect }}$. After that, the entire batch is transported to the serviceable stock. Let $\xi_{i}$ be the arrival time of the $i$ th batch to the on-hand serviceable inventory $x\left(\right.$.). Then, $\xi_{i}=\delta_{i}+n \tau_{\text {insp }}$, if the $i$ th batch is accepted, and $\xi_{i}=\delta_{i}+Q \tau_{\text {insp }}+p^{i} Q \tau_{\text {rect }}$, if not. We assume that always we have $\xi_{i} \leq \delta_{i+1}(i=1 . . N)$ which means that the quality control operations of the $i$ th batch is finished before the end of the production cycle of the next $(i+1)$ th batch.

The probability $P_{a}$ of accepting the $i$ th batch containing $k$ nonconforming items can be calculated using the binomial probability distribution (Besterfield, 2009), as follows: 


$$
P_{a}\left(p^{i} \mid n, c\right)=\sum_{k=0}^{c} \frac{n !}{k !(n-k) !}\left(p^{i}\right)^{k}\left(1-p^{i}\right)^{n-k}
$$

As the accepted batches do not receive 100\% inspection, some nonconforming items will remain in the outgoing batches and therefore transmitted to the consumer. The long-term average proportion of nonconforming items existing in the final stock, also named the Average Outgoing Quality $A O Q$, can be calculated using the following formulae (Schilling and Neubauer, 2009):

$$
A O Q=\frac{E[p] \cdot P_{a}(E[p]) \cdot(Q-n)}{Q}
$$

We assume that all nonconforming items transmitted to the consumer are returned and replaced by good ones. While the demand/backlog is filled, the replaced quantity at each time $t$ can be considered proportional to the demand rate $d$. Consequently, the instantaneous real demand rate becomes equal to $d /(1-\beta(t) A O Q)$, where, $\beta(t)$ measures the instantaneous service level of the demand/backlog. $\beta(t)=1$, if $x(t)>0$ or $\alpha(t)=1$, and $\beta(t)=0$, otherwise.

\subsection{Production control policy}

In the literature, it was shown that the optimal production control policy for continuousflow unreliable manufacturing systems is of a hedging point policy (HPP) type (Bielecki and Kumar, 1988). For unreliable batch manufacturing systems with delays which cannot be considered as continuous-flow systems, Bouslah et al. (2012) showed that the optimal feedback control policy can be closely approximated by a base-stock policy expressed by a modified HPP. When the batches produced need to be transported for a non-negligible delay to the serviceable stock, the authors assumed that the feedback inventory control is based on the concept of the inventory position which includes the on-hand inventory in the final stock and the total pending quantities in transportation as in Mourani et al. (2008) and Li et al. (2009). In our study, we define the inventory position $y(t)$ at each time $t$ as the sum of the stock (inventory/backlog) level $x(t)$ and the total amount of batches under sampling, 100\% inspection and rectification. Considering the effect of the outgoing quality on the real demand rate, the modified HPP is formulated as follows:

$$
\left.\left.u^{i}(t \in] \theta_{i=1,2, \ldots \infty}, \theta_{i+1}\right], \alpha\right)=\left\{\begin{array}{cc}
\alpha(t) u_{\max } & \text { if }\left(y\left(\theta_{i}^{+}\right)<Z\right) \\
\frac{\alpha(t) d}{1-A O Q} & \text { if }\left(y\left(\theta_{i}^{+}\right)=Z\right) \\
0 & \text { if }\left(y\left(\delta_{i}^{+}\right)>Z\right)
\end{array}\right.
$$

In fact, the production rate $u^{i}($.$) of the i$ th batch can take three possible levels depending on the inventory position state and the instantaneous system availability, as follows:

1. If the inventory position at the beginning of the the $i$ th production cycle $\left(t=\theta_{i}\right)$ is strictly below the threshold level $Z$, and while the production system is available $(\alpha(t)=1)$, the corresponding $i$ th batch is manufactured at the maximum production rate 
$u_{\max }$. Such a case happens when the production is restarting just after a corrective maintenance.

2. If the inventory position at the beginning of the $i$ th production cycle is exactly equal to the threshold level $\mathrm{Z}$, and while the production system is available $(\alpha(t)=1)$, the production rate of the $i$ th batch is set to the demand rate $d /(1-A O Q)$ in order to maintain the on-hand inventory position.

3. If the inventory position at a time $\left.t \in] \theta_{i}, \theta_{i+1}\right]$ becomes strictly greater than the threshold level $Z$ the manufacturing is stopped $(u()=0$.$) until the inventory position$ takes back the threshold level $Z$ by the effect of the demand. Also, when the production system becomes unavailable $(\alpha(t)=0)$, the production is stopped immediately.

\section{Optimization problem formulation}

The dynamics of production $q($.$) , inventory position y($.$) and final inventory level x($. can be described respectively by the following difference and differential equations:

$$
\begin{aligned}
& \left.\frac{d q(t)}{d t}=u(t, \alpha), q(0)=q, \forall t \in\right] \theta_{i}, \delta_{i}[, \\
& q\left(\delta_{i}^{+}\right)=q\left(\delta_{i}^{-}\right)-Q, \\
& \left.\frac{d y(t)}{d t}=\frac{-d}{1-\beta(t) A O Q}, y(0)=y, \forall t \in\right] \delta_{i}, \delta_{i+1}[, \\
& y\left(\delta_{i}^{+}\right)=y\left(\delta_{i}^{-}\right)+Q, \\
& \left.\frac{d x(t)}{d t}=\frac{-d}{1-\beta(t) A O Q}, x(0)=x, \forall t \in\right] \xi_{i}, \xi_{i+1}[, \\
& x\left(\xi_{i}^{+}\right)=x\left(\xi_{i}^{-}\right)+Q, \\
& \forall i=1, . ., N
\end{aligned}
$$

where, $q, x$ and $y$ denote respectively the WIP level, the inventory position and the finished product inventory level at initial time. $\delta_{i}^{-}$and $\delta_{i}^{+}$denote the left and right boundaries of the $i$ th production cycle end time $\delta_{i}$, and $\xi_{i}^{-}$and $\xi_{i}^{+}$denote the left and right boundaries of the arrival time $\xi i$ of the $i$ th batch to the final stock $x($.).

Figure 2 depicts graphically the dynamic of production (batch-in-process level $q(t)$ ), and the evolution of the serviceable inventory level $x(t)$ as function of instantaneous system availability $\alpha(t)$, production cycle length, and acceptance or not of batches produced. 


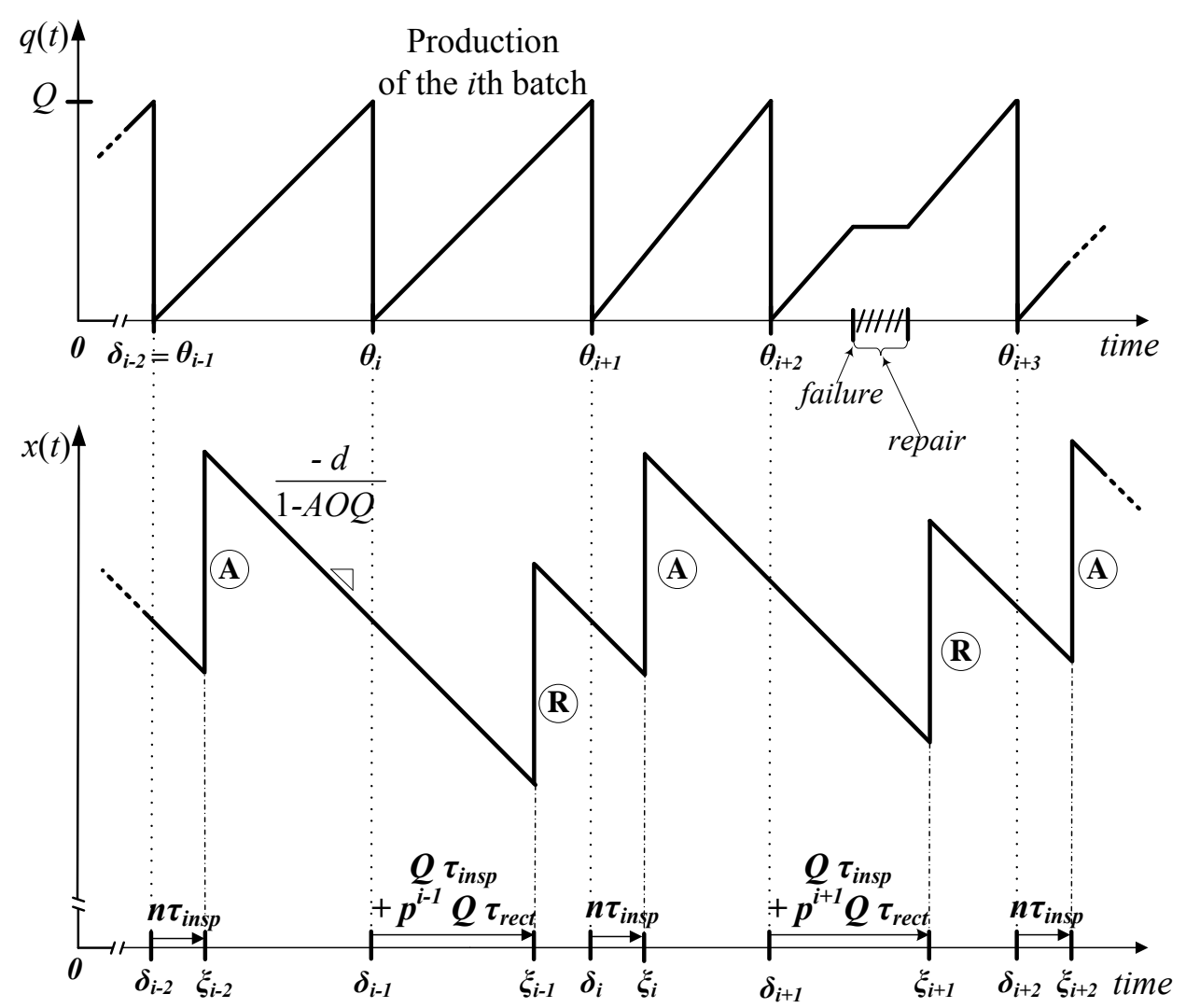

A Accepted batches (R) Rejected batches

Figure 2. Production and inventory level dynamics.

Our objective is to determine the optimal batch size $Q$, the optimal hedging level $Z$ and the economic sampling plan design $(n, c)$ which minimize the long-term expected total cost ETC(.) per unit time including; the average total holding cost which includes the storage of the work-in-process (batch-in-process, batches under sampling, $100 \%$ inspection and rectification) and the final inventory stock $x($.$) , the average backlog cost,$ the average cost of sampling, the average costs of $100 \%$ inspection and rectification of the rejected batches, the average cost of transportation, and the average cost of replacement of nonconforming items sold to the consumer. Note that the consumer satisfaction is considered in the expected total cost function by penalizing the backlog (product availability in the producer serviceable inventory) and the replacement of returned nonconforming items (quality of product).

Any admissible solution $(Q, Z, n, c)$ must satisfy the following constraints:

$0<Q \leq \min \left\{Q_{\max }^{\text {bip }}, Q_{\max }^{\text {insp }}\right\}$

$0<Z \leq Z_{\max }$

$0<c \leq n \leq n_{\max }$

$Q, Z, n, c:$ integers 
where, $Q_{\max }^{\text {bip }}$ is the maximum batch-in-process storage capacity, $Q_{\max }^{\text {insp }}$ is the maximum inspection area capacity, $Z_{\max }$ is the maximum storage capacity of the inventory position and $n_{\max }$ is the maximum sample size. The constraint of the maximum sample size was used by Ravindran et al. (1986) and in practice it represents the capacity constraint of resources allowed to sampling.

Therefore, the optimization model associated to the problem under study can be described as follows:

$$
\left\{\begin{aligned}
\text { Minimize } E T C(Q, Z, n, c) & =C^{+}\left(E[q]+E\left[y^{+}\right]\right)+C^{-} E\left[x^{-}\right] & & \text {(inventory and backlog costs) } \\
& +C_{\text {insp }} n E\left[N_{\infty}\right] & & \text { (sampling cost) } \\
& +\left(1-P_{a}(E[p])\right) C_{\text {insp }}(Q-n) E\left[N_{\infty}\right] & & (100 \% \text { inspection cost) } \\
& +\left(1-P_{a}(E[p])\right) C_{r e c t} E[p] Q E\left[N_{\infty}\right] & & \text { (rectification cost) } \\
& +P_{a}(E[p]) C_{r e p} E[p](Q-n) E\left[N_{\infty}\right] & & \text { (replacement cost) } \\
& +C_{t r} E\left[N_{\infty}\right] & & \text { (transportation cost) }
\end{aligned}\right.
$$

Subject to Constraints (1)-(2)-(3)-(4)-(5)

where, $E[q]=\lim _{T \rightarrow+\infty} \frac{1}{T} \int_{0}^{T} q(t) d t, E\left[y^{+}\right]=\lim _{T \rightarrow+\infty} \frac{1}{T} \int_{0}^{T} \max (0, y(t)) d t$,

$E\left[x^{-}\right]=\lim _{T \rightarrow+\infty} \frac{1}{T} \int_{0}^{T} \max (0,-x(t)) d t, E\left[N_{\infty}\right]$ is the long-term expected number of batches produced per unit time, and $E[p]$ is the expected proportion of nonconforming items.

The decision variables $(Q, Z, n, c)$ are integer numbers. Moreover, the expected total cost function $E T C($.$) is nonlinear due to the E[q], E\left[y^{+}\right], E\left[x^{-}\right]$and $P_{a}($.$) terms. Also,$ the constraints (3) and (4) are nonlinear and stochastic. Hence, this model is a stochastic, nonlinear and integer programming problem which is difficult and complex. However, the expected total cost ETC(.) is convex in $Q$ and $Z$. In fact, the sum of the inventory, backlog and transportation costs is a convex function in $Q$ and $Z$ as shown in Bouslah et al. (2012), while 100\% inspection, rectification and replacement costs are linear with respect to $Q$. In addition, when the sampling cost is assumed to be linear or strictly convex function in the sample size $n$, the existence of a global optimum sampling plan $\left(n^{*}, c^{*}\right)$ which minimizes the sum of all quality related costs was proved by Moskowitz and Berry (1976) and Moskowitz et al. (1979). These objective function ETC(.) properties are exploited in developing the resolution approach procedure.

\section{Resolution approach}

\subsection{Resolution approach procedure}

In this section, we propose a resolution approach which combines an enumeration procedure with respect to the acceptance number $c$ and a simulation based-optimization approach to optimize the expected total cost $\operatorname{ETC}_{c}(Q, Z, n)$ for each given acceptance 
number. The enumeration procedure approach has been used by Peters et al. (1988) and Ben-Daya and Noman (2008) to determine the optimal single sampling plan design for supplier quality control. However, the simulation based-optimization approach which combines simulation, design of experiments, statistical analysis and response surface methodology has been widely employed in literature to design manufacturing control policies as in Safizadeh and Thornton (1984) and Gharbi and Kenne (2000). To implement the resolution approach we developed and validated a simulation model representing the real dynamic of the system as described in section 4 . The simulation model is used to calculate the expected total cost for given $(Q, Z, n, c)$. The proposed procedure can be summarized by the following steps:

Step 0. Set $c=0$.

Step 1. For a fixed acceptance number $c$, determine $\psi_{c}(Q, Z, n)$ a quadratic approximation function of the expected total cost $\operatorname{ETC}_{c}(Q, Z, n)$ using a combination of design of experiments, regression analysis and response surface methodology. Optimize $\psi_{c}(Q, Z, n)$ under constraints (5). Find $Q_{c}^{*}, Z_{c}^{*}$ and $n_{c}^{*}$ and calculate $\psi_{c}\left(Q_{c}^{*}, Z_{c}^{*}, n_{c}^{*}\right)$. If $c=0, \operatorname{set} c=1$.

Step 2. If $\psi_{c}\left(Q_{c}^{*}, Z_{c}^{*}, n_{c}^{*}\right) \leq \psi_{c-1}\left(Q_{c-1}^{*}, Z_{c-1}^{*}, n_{c-1}^{*}\right)$ and $n_{c}^{*} \leq n_{\max }$, set $c=c+1$. Go to step 1 .

Step 3. If $n_{c}^{*}>n_{\max }$, the optimal control batch size, the optimal hedging level, the optimal sample size and acceptance number are respectively $Q_{c-1}^{*}, Z_{c-1}^{*}, n_{c-1}^{*}$ and $c-1$. Otherwise, find the optimal solution $Q_{c}^{*}, Z_{c}^{*}, n_{c}^{*}$ and $c^{*}$ such that

$$
\psi_{c-1}\left(Q_{c-1}^{*}, Z_{c-1}^{*}, n_{c-1}^{*}\right) \geq \psi_{c}\left(Q_{c}^{*}, Z_{c}^{*}, n_{c}^{*}\right) \leq \psi_{c+1}\left(Q_{c+1}^{*}, Z_{c+1}^{*}, n_{c+1}^{*}\right) .
$$

In step 1 , we use, for given acceptance number $c$, an experimental design plan to define how the control factors $(Q, Z, n)$ should be varied in order to determine the effects of the design factors and their interactions (i.e. analysis of variance ANOVA) on the incurred total cost. Then, the effects (design factors and their interactions) are considered as input to a regression analysis which is used in conjunction with the response surface methodology, to fit the relationship between the cost and the input factors (Montgomery, 2008). Given the convexity of the $\operatorname{ETC}_{c}(Q, Z, n)$, as mentioned in section 4, it can be approximated by a second-order function precisely when the experimental region of $(Q, Z, n)$ is chosen correspondingly to the region of the global optimum. We denote by $\psi_{c}($.) the continuous function of $Q, Z$ and $n$ for a fixed acceptance number $c$, fitting a second-order regression model and relating the response variable $\operatorname{ETC}_{c}($.$) to$ the design factors. This function is called the response surface and takes the following equation:

$\psi_{c}(Q, Z, n)=\beta_{0}+\beta_{1} Q+\beta_{2} Z+\beta_{3} n+\beta_{12} Q Z+\beta_{13} Q n+\beta_{23} Z n+\beta_{11} Q^{2}+\beta_{22} Z^{2}+\beta_{33} n^{2}+\varepsilon$

where, $\beta_{0}, \beta_{i}(\mathrm{i}=1,3), \beta_{12}, \beta_{13}, \beta_{23}, \beta_{i i}(\mathrm{i}=1,3)$ are unknown parameters to be estimated from the collected simulation data, and $\varepsilon$ is a random error.

\subsection{Simulation model}


A combined discrete-continuous model was developed using the SIMAN simulation language with $\mathrm{C}++$ subroutines (Pegden et al., 1995), and then executed through the ARENA simulation software. The advantage of using a combined discrete-continuous model is to reduce the execution time (Lavoie et al., 2007), and to model accurately the real production and inventory dynamics of the manufacturing system.

The simulation model can be described following the sequence of numbers appearing in Figure 3, as follows:

(0) INITIALIZATION: setting the values of the parameters $\left(u_{\max }, d, c, \tau_{\text {insp }}, \tau_{\text {rect }}\right)$, the simulation run-time $T_{\infty}$, the decision variables $(Q, Z, n)$, the unit partial costs $\left(C^{+}, C^{+}\right.$, $\left.C_{i n s p}, C_{\text {rect }}, C_{r e p}, C_{t r}\right)$, the initial states $(q, x, y)$ and the probability distributions of the proportion of defective items $p($.$) , Time To Failures TTF and Time To Repair TTR. The$ simulation run-time $T_{\infty}$ is set long enough to guarantee that the random events during the simulation run are observed sufficiently and that the steady-state of the model is reached. Note that the model is developed to accept any probability distribution for the $p, T T F$ and TTR.

(1) The DEMAND RATE is used as an input of the state equations. In order to represent the real system operation, we define the instantaneous real demand rate as $d /(1-A O Q(t))$, where, $A O Q(t)$ is the instantaneous average outgoing quality. The $A O Q(t)$ can be calculated using the following formulae:

$$
A O Q(t)=\frac{\sum_{i=0 / a^{i}=1}^{N(t)} p^{i}(Q-n)}{(N(t)+1) Q}
$$

where, $a^{i}=1$, if the batch is accepted, and $a^{i}=0$, if not. $N(t)$ is the cumulative number of batches arrived to the serviceable inventory $x($.$) at time each t$. 


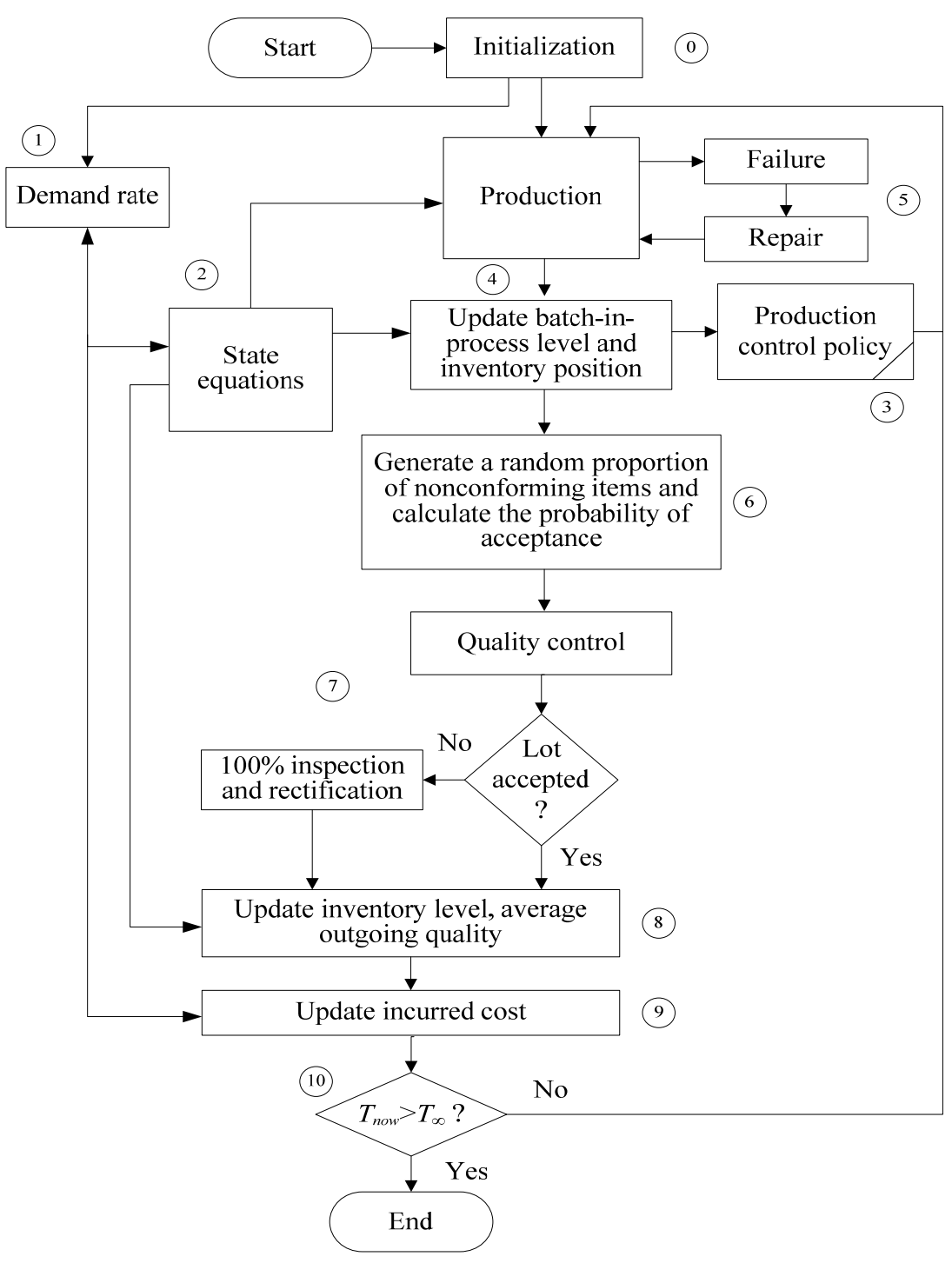

Figure 3. Simulation block diagram.

(2) The STATE EQUATIONS are described by the differential equations of (4) and are modeled with a $\mathrm{C}++$ language insert. When a batch is released at the end of production cycle or a batch enters into the serviceable inventory $x($.$) , a signal is send to the \mathrm{C}++$ routines to update the values of the variables $q(),. y($.$) and x($.$) using the difference$ equations of (4).

(3) The PRODUCTION CONTROL POLICY is implemented using equation (3). At the end of each production cycle, the control policy is triggered to determine the production rate of the next production cycle depending on the current position inventory and the system availability.

(4) The PRODUCTION block models the processing delay which is calculated by dividing the batch size $Q$ by the production rate $u^{i}($.). When the batch production is completed, the original entity is sent back to the PRODUCTION CONTROL POLICY block and a duplicated entity is created and sent to an UPDATE block where the batch- 
in-process level is impulsively annulled and the batch size is added to the inventory position.

(5) The blocks FAILURE and REPAIR model respectively the failure and repair events as a close loop following the TTF and TTR distributions.

6 A random proportion of nonconforming items $p^{i}$ is attributed to each batch produced following the $p($.$) probability distribution, and the associated probability of acceptance$ $P_{a}($.$) is calculated using Eq. (1).$

(7) Then, the entity (batch produced) holds in QUALITY CONTROL block for sampling during $n \times \tau_{\text {insp }}$. The decision to accept or reject the batch is modeled by a probabilistic branch function of SIMAN using the probability of acceptance $P_{a}($.$) attributed to each$ batch. Rejected batches hold in an additional block for $100 \%$ inspection and rectification during $Q \tau_{\text {insp }}+p^{i} Q \tau_{\text {rect }}$.

8 When a batch arrives to the serviceable final stock, the corresponding entity impulsively updates the inventory level as in (4). The average outgoing quantity $A O Q($.) is also updated using Eq. (8).

9 This block updates instantly the incurred cost according to the instantaneous values of the different variables and the unit costs.

(10) Simulation run-time control: if the current time $T_{\text {now }}$ exceeds the predefined simulation run-time $T_{\infty}$, the simulation run is stopped.

\subsection{Validation of the simulation model}

To validate that the conceptual simulation model represents accurately the system under study, we graphically verify that the dynamics of production and inventory operates correctly according to Eq. (3) and Eqs. (5). Figure 4 represents a sample of the trajectories evolution of the production rate, the inventory position and the inventory during simulation run. The graphic shows how the production rate value changes in response to changes in the inventory position and the system availability states as intended. The impact of batches rejection on the inventory level dynamic is clearly shown by a significant time lag between the inventory level and the inventory position trajectories due to the $100 \%$ inspection and rectification operations. In addition, we verified the behaviour of the observed operating characteristic (OC) curve (obtained by simulation) of various given sampling plans comparing with their associated theoretical OC curves (obtained using Eq. (1)). We always found that the observed OC curve coincides with the theoretical OC curve which confirms the accuracy of the quality control modeling in the simulation model. 


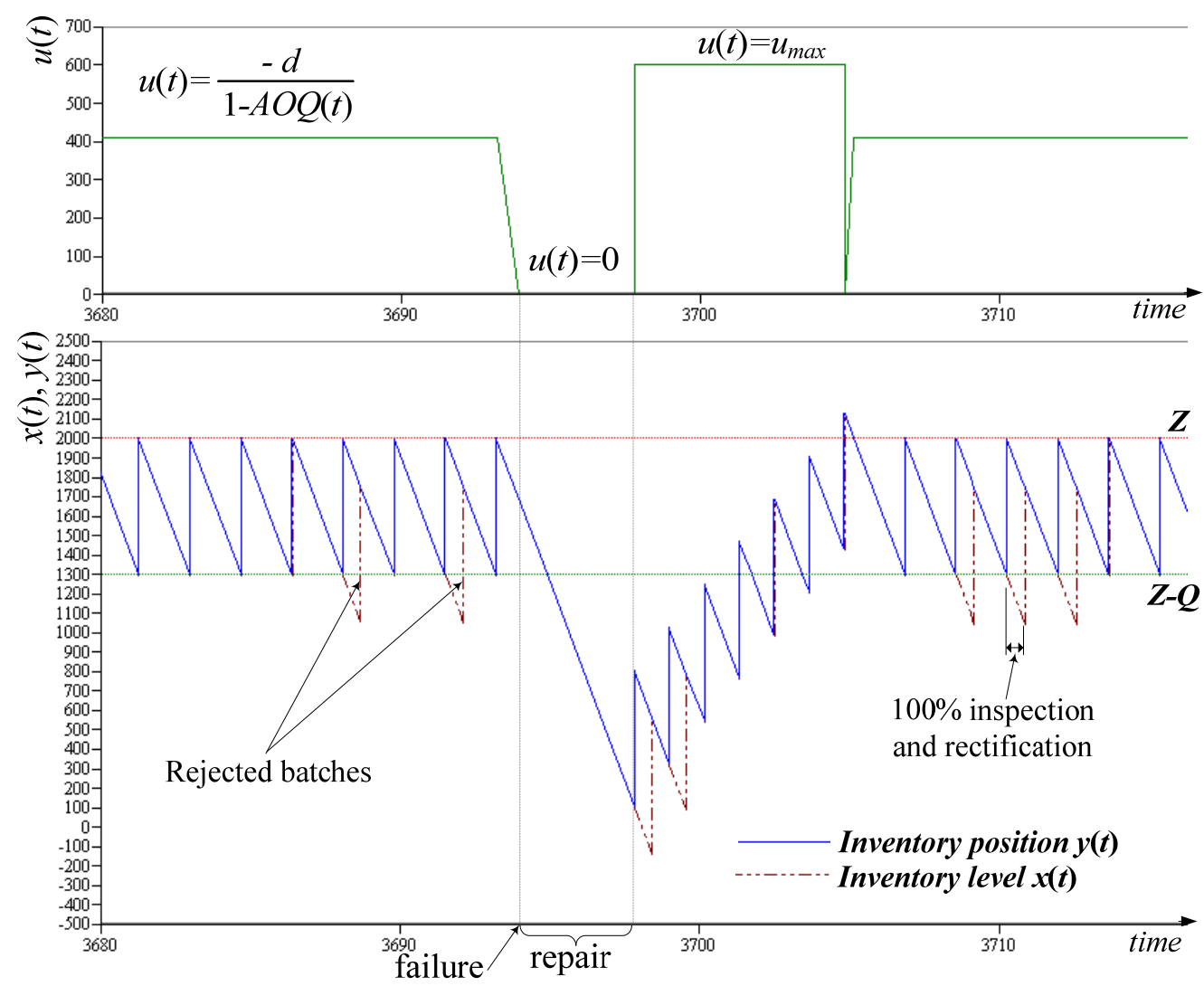

Figure 4. Production rate and inventory position/level evolutions during simulation run.

\section{Numerical example and results analysis}

In this section, we present a numerical example to illustrate the resolution approach procedure and to conduct a sensitivity analysis of the optimal solution with respect to the model parameters. Let us consider the following parameters in appropriate units: $u_{\max }=600, d=400, n_{\max }=130, Z_{\max }=4500, Q_{\max }^{\text {bip }}=Q_{\max }^{\text {insp }}=1500, \tau_{\text {insp }}=5 \times 10^{-4}, \tau_{\text {rect }}=10^{-3}$, $C^{+}=0.1, C^{-}=1.5, C_{t r}=250, C_{\text {insp }}=0.25, C_{\text {rect }}=5, C_{\text {rep }}=12.5$. The stochastic variables are as follows: $p \sim \operatorname{Uniform}(0.02,0.04), T T F \sim \operatorname{LogNormal}(50,5)$ and $T T R \sim \operatorname{Gamma}(0.5,10)$. The expected proportion of nonconforming items $E[p]$ is equal to 0.03 . We define the expected system availability rate as $E[\alpha]=M T T F /(M T T F+M T T R)$ where $M T T F$ is the mean time to failure and MTTR is the mean time to repair. From the above TTF and TTR distributions, the expected system availability rate $E[\alpha]$ is equal to $90.91 \%$.

For given acceptance number $c$, simulation runs are carried out according to a three factors Box-Behnken experimental plan (15 runs) with four replications for each combination of factors $(Q, Z, n)$. This type of design is desired because of its rotatable feature and its efficiently in terms of number of required runs (Montgomery, 2008). In order to ensure that the steady-state is reached, the duration of each simulation run is set to 500,000 units of time. The simulated data is carried out using statistical software (STATISTICA) to seek a second order regression model fitting the response variable $\operatorname{ETC}_{c}(Q, Z, n)$. 
Table 1. Results of the application of the resolution procedure.

\begin{tabular}{cccccc}
\hline$c$ & $R_{\text {adjusted }}^{2}$ & $Q^{*}$ & $Z^{*}$ & $n^{*}$ & $\psi_{c}\left(Q^{*}, Z^{*}, n^{*}\right)$ \\
\hline 0 & 0.9842 & 1176 & 2658 & 5 & 534.61 \\
1 & 0.9826 & 1154 & 2664 & 12 & 533.12 \\
2 & 0.9831 & 1148 & 2665 & 26 & 532.42 \\
3 & 0.9829 & 1138 & 2665 & 51 & 531.29 \\
4 & 0.9824 & 1127 & 2680 & 92 & 530.32 \\
5 & 0.9804 & 1104 & 2681 & 143 & 529.04 \\
\hline
\end{tabular}

Table 1 presents the results obtained from the application of the resolution approach procedure to the present numerical example. We remark that the R-squared adjusted value for all acceptance number is always greater than $98.00 \%$. This states that more than $98.00 \%$ of the observed variability in the expected total costs is explained by the models. This confirms that the expected total $\operatorname{cost} \operatorname{ETC}_{c}(Q, Z, n)$ for each fixed acceptance number $c$ can be closely fitted by second-order model (Montgomery, 2008). It should be mentioned here that ANOVA analysis of fitting models for all acceptance number showed that the linear and quadratic effects of the factors $(Q, Z, n)$ and their interactions, $Q . Z, Q . n$ and $Z . n$, are significant for the response variable at a 0.05 level of significance. Figure 5 shows the Pareto chart of standardized effects for the BoxBehnken design when the acceptance number is equal to 4 .

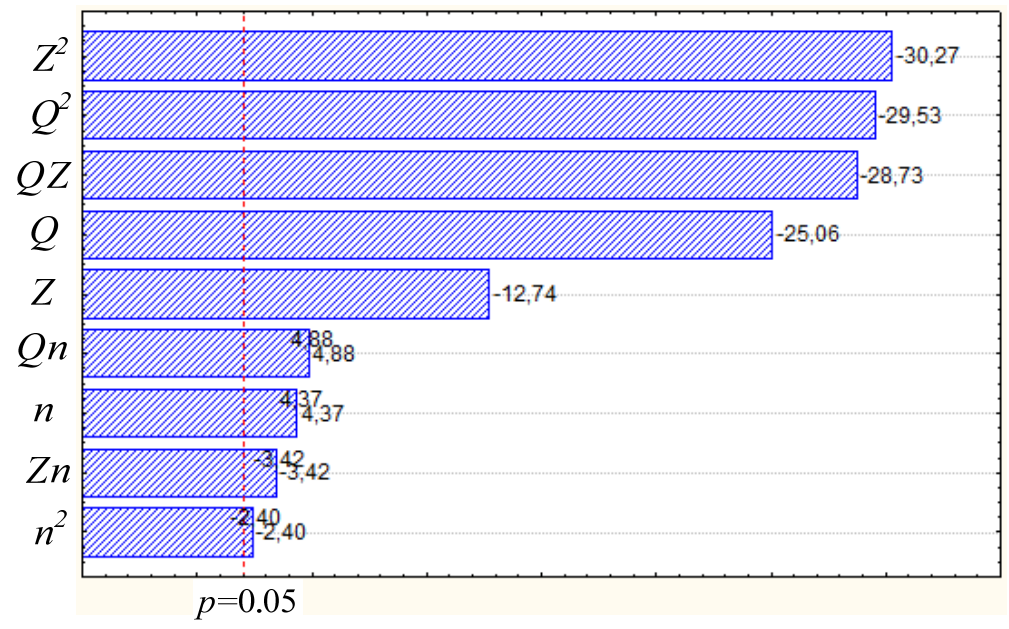

Figure 5. Pareto chart of standardized effects for the three factors Box-Behnken experimental design $(c=4)$.

From Table 1, the optimal acceptance number $c^{*}$ is 4 because it corresponds to the minimum expected total cost that satisfies the constraint $n \leq n_{\max }$. For all acceptance number greater than $c^{*}$, the optimal sample size $n^{*}$ exceeds the maximum sample size $n_{\max }$. Using STATISTICA the related second order cost function is given by:

$$
\begin{aligned}
& \psi_{4}(Q, Z, n)=865.69-107.54 \times 10^{-3} Q-201.98 \times 10^{-3} Z-89.25 \times 10^{-3} n-94.23 \times 10^{-6} Q Z \\
& +240.23 \times 10^{-6} Q n-89.78 \times 10^{-6} Z n+150.01 \times 10^{-6} Q^{2}+59.02 \times 10^{-6} Z^{2}+322.97 \times 10^{-6} n^{2}+\varepsilon
\end{aligned}
$$



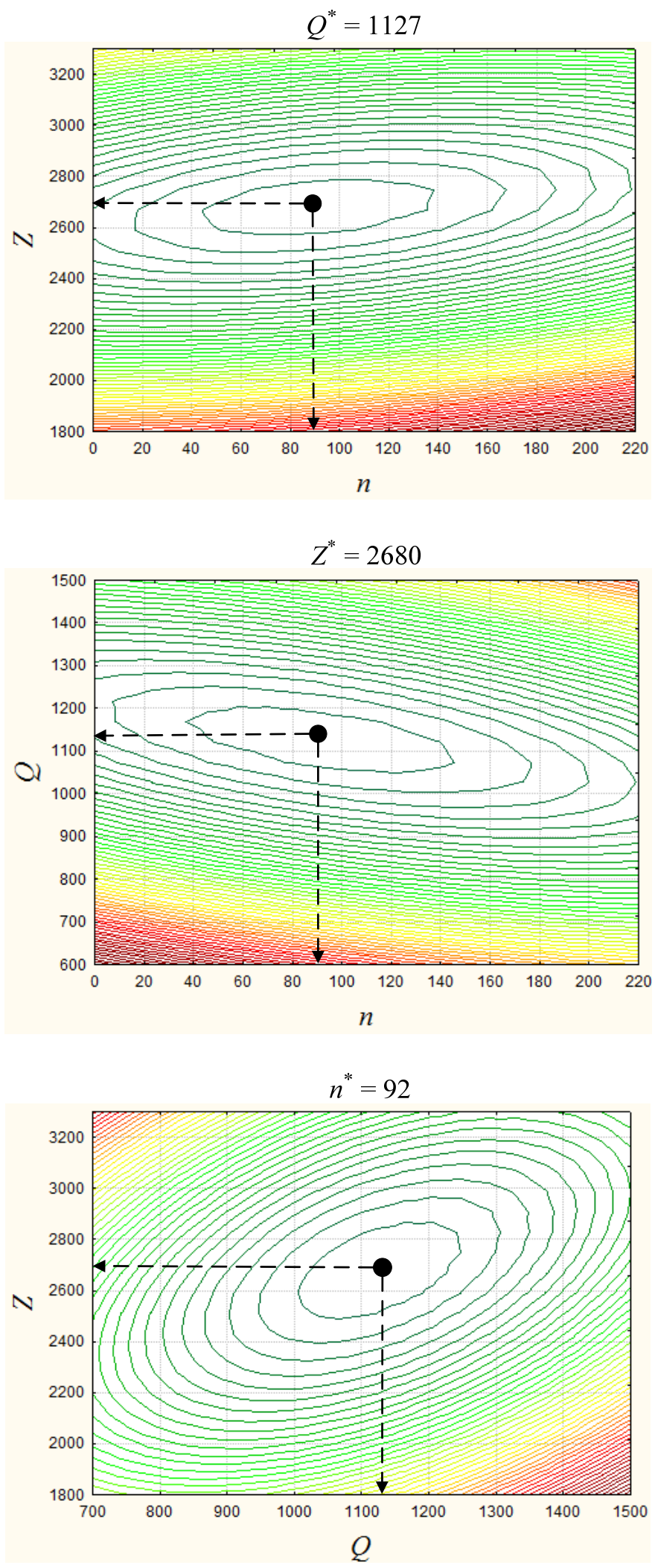

Figure 6. Contour plots of the $E T C_{c}($.$) predicted from the quadratic model (c=4)$. 
The optimization of the quadratic function $\psi_{4}(Q, Z, n)$ gives a minimum expected total cost 530.32 located at $Q^{*}=1127, Z^{*}=2680$ and $n^{*}=92$ as shown in Figure 6. Also, from Table 1, we remark that the differences between the $\psi_{c}\left(Q^{*}, Z^{*}, n^{*}\right)$ for all acceptance number $c\left(c \neq c^{*}\right)$ and $\psi_{c^{*}}\left(Q^{*}, Z^{*}, n^{*}\right)$ are less than $1 \%$. This can be explained by the possible existence of several local minima around the global optimum of the expected total cost as shown by Moskowitz and Berry (1976) and Peters et al. (1988).

A sensitivity analysis of the production and quality control policies is conducted with respect to model parameters (costs, inspection delay, system availability and proportion of nonconforming items) by varying their values above and below its baseline value. Ten sets of experiments are achieved in order to understand how the optimal control parameters $\left(Q^{*}, Z^{*}, n^{*}, c^{*}\right)$ vary with changes of the model parameters and to show the applicability of the resolution approach for ranges of system parameters. The results are summarized in Table 2, where the variation of the optimal control parameters $\left(Q^{*}, Z^{*}\right.$, $\left.n^{*}, c^{*}\right)$, the optimal expected total cost ETC(.) and the 'optimal' probability of acceptance $P_{a}^{*}=P_{a}\left(E[p] \mid n^{*}, c^{*}\right)$ are highlighted (i.e., respectively $\Delta Q^{*}, \Delta Z^{*}, \Delta n^{*}, \Delta c^{*}$, $\triangle E T C^{*}$, and $\Delta P_{a}{ }^{*}$ ). Note that the probability of acceptance $P_{a}^{*}$ is used to measure the sampling plan severity. When the probability of acceptance increases the sampling plan severity becomes reduced. Inversely, when the probability of acceptance increases the sampling plan severity becomes tightened.

- Variation of the inventory cost (Set I): When the inventory cost $C^{+}$increases, the optimal hedging threshold $Z^{*}$ decreases in order to avoid further inventory costs. Consequently, the optimal batch size $Q^{*}$ decreases to reduce production, $100 \%$ inspection and rectification delays and therefore ensures a better supply to the serviceable inventory $x($.). The optimal sampling plan severity becomes reduced in order to minimize the holding cost of rejected batches during the $100 \%$ inspection and rectification operations. Note that the decrease in inventory cost produces the opposite effects.

- Variation of backlog cost (Set II): When the backlog cost $C^{-}$increases, the production-inventory control policy reacts by increasing the hedging level $Z^{*}$ (i.e., increasing the safety stock limit) to provide a better protection to the system against shortages. The optimal batch size $Q^{*}$ decreases slightly to reduce batch processing delays which improves the supply of the serviceable inventory. The optimal sampling plan becomes more tightened which means that more batches are rejected. This can be explained as follows: first, remind that the demand rate is time-varying depending on the instantaneous service level of the demand/backlog (section 3.2). Because the safety stock limit increases, the long-term service level increases as the sales increase also. Given that the quantity of nonconforming items returned from consumer is proportional to sales, and in order to avoid further replacement cost, the quality control policy reacts by tightening the batches acceptance. The decrease in backlog cost produces the opposite effects. 
- Variation of transportation cost (Set III): When the transportation cost $C_{t r}$ is higher, the frequency of batches transportation needs to be reduced in order to minimize the total transportation cost. Consequently, the optimal batch size $Q^{*}$ increases, and leads to a systematic increase in the optimal hedging level $Z^{*}$ in order to protect the system from backlogs. The optimal sampling plan severity becomes reduced in order to reduce batches rejection and give preference to keep the serviceable inventory at a high level. The opposite effects are well observed when the transportation cost decreases.

- Variation of inspection cost (Set IV): When the inspection cost $C_{\text {insp }}$ increases, the optimal sampling plan severity becomes reduced in order to minimize rejection of batches produced and therefore reduce the $100 \%$ inspection cost. The optimal hedging level $Z^{*}$ slightly decreases due to the decrease of the long-term average $100 \%$ inspection and rectification delays. As a result, the optimal batch size $Q^{*}$ increases. Note that the decrease in inspection cost conducts to the opposite effects.

- Variation of rectification cost (Set V): Similarly to the inspection cost, the increase in the rectification $\cos t C_{r e c t}$ results in reducing the severity of the optimal sampling plan in order to minimize rejection of batches and consequently reduce the long-term rectification cost. The optimal hedging level $Z^{*}$ slightly decreases because the long-term decrease of batch processing delays after production. This causes an increase of the optimal batch size.

- Variation of replacement cost (Set VI): When the replacement cost $C_{r e p}$ of returned nonconforming items increases, more $100 \%$ inspection and rectification operations are needed to reduce the outgoing quality which explains the severity tightening of the optimal sampling plan. Consequently, smaller batch size should be produced to ensure a regular supply of the serviceable inventory. The decrease in replacement cost conducts to the opposite effects.

- Variation of inspection delay (Set VII): When the inspection delay increases, the 'optimal' probability of acceptance $P_{a}{ }^{*}$ increases in order to reduce the long-term average $100 \%$ inspection delay. Therefore, the optimal hedging level $Z^{*}$ decreases slightly and results in a minor increase of the optimal batch size. The decrease in inspection delay produces the opposite effects.

- Variation of system availability (Set VIII and IX): First, recall that when the Mean Time To Failures MTTF increases (decreases) or the Mean Time To Repair MTTR decreases (increases), the average availability system increases (decreases). When the system availability decreases (MTTF decreases or MTTR increases), the optimal hedging level $Z^{*}$ increases in order to protect the serviceable inventory against the risk of shortages becoming higher. As a result, the economic sampling plan severity is reduced in order to save $100 \%$ inspection and rectification delays for rejected batches and give better supply to the serviceable inventory. Note that an increase in the MTTF or a decrease in the MTTR produces the opposite effects. 
Table 2. Sensitivity analysis for model parameters.

\begin{tabular}{|c|c|c|c|c|c|c|c|c|c|c|c|c|}
\hline Sets & Parameters & Changes & $Q^{*}$ & $Z^{*}$ & $n^{*}$ & $c^{*}$ & $E T C^{*}$ & $P_{a}^{*}$ & $\Delta Q^{*}(\%)$ & $\Delta Z^{*}(\%)$ & $\Delta \operatorname{ETC}^{*}(\%)$ & $\Delta P_{a}^{*}(\%)$ \\
\hline Base & - & - & 1127 & 2680 & 92 & 4 & 530.32 & 0.859 & - & - & - & - \\
\hline Set I & $C^{+}$ & $\begin{array}{l}-50 \% \\
+50 \%\end{array}$ & $\begin{array}{r}1275 \\
953\end{array}$ & $\begin{array}{l}3233 \\
2162\end{array}$ & $\begin{array}{l}122 \\
110\end{array}$ & $\begin{array}{l}4 \\
5\end{array}$ & $\begin{array}{l}399.82 \\
634.39\end{array}$ & $\begin{array}{l}0.696 \\
0.886\end{array}$ & $\begin{array}{l}+13.13 \% \\
-15.44 \%\end{array}$ & $\begin{array}{l}+20.63 \% \\
-19.33 \%\end{array}$ & $\begin{array}{r}-24.61 \% \\
+19.62 \%\end{array}$ & $\begin{array}{r}-18.98 \% \\
+3.14 \%\end{array}$ \\
\hline Set II & $C^{-}$ & $\begin{array}{l}-50 \% \\
+50 \%\end{array}$ & $\begin{array}{l}1141 \\
1100\end{array}$ & $\begin{array}{l}1877 \\
2945\end{array}$ & $\begin{array}{l}123 \\
112\end{array}$ & $\begin{array}{l}6 \\
4\end{array}$ & $\begin{array}{l}481.42 \\
551.97\end{array}$ & $\begin{array}{l}0.922 \\
0.753\end{array}$ & $\begin{array}{r}+1.24 \% \\
-2.40 \%\end{array}$ & $\begin{array}{r}-29.96 \% \\
+9.89 \%\end{array}$ & $\begin{array}{r}-9.22 \% \\
+4.08 \%\end{array}$ & $\begin{array}{r}+7.35 \% \\
-12.34 \%\end{array}$ \\
\hline Set III & $C_{t r}$ & $\begin{array}{r}-50 \% \\
+50 \%\end{array}$ & $\begin{array}{r}777 \\
1261\end{array}$ & $\begin{array}{l}2418 \\
2776\end{array}$ & $\begin{array}{l}77 \\
95\end{array}$ & $\begin{array}{l}3 \\
5\end{array}$ & $\begin{array}{l}479.41 \\
571.39\end{array}$ & $\begin{array}{l}0.799 \\
0.933\end{array}$ & $\begin{array}{l}-31.06 \% \\
+11.89 \%\end{array}$ & $\begin{array}{r}-9.78 \% \\
+3.58 \%\end{array}$ & $\begin{array}{r}-9.60 \% \\
+7.74 \%\end{array}$ & $\begin{array}{l}-6.93 \% \\
+8.66 \%\end{array}$ \\
\hline Set IV & $C_{i n s p}$ & $\begin{array}{l}-25 \% \\
+25 \%\end{array}$ & $\begin{array}{l}1042 \\
1139\end{array}$ & $\begin{array}{l}2738 \\
2641\end{array}$ & $\begin{array}{l}117 \\
130\end{array}$ & $\begin{array}{r}1 \\
11\end{array}$ & $\begin{array}{r}519.7 \\
532.15\end{array}$ & $\begin{array}{l}0.131 \\
0.999\end{array}$ & $\begin{array}{l}-7.54 \% \\
+1.06 \%\end{array}$ & $\begin{array}{r}+2.16 \% \\
-1.46 \%\end{array}$ & $\begin{array}{l}-2.00 \% \\
+0.35 \%\end{array}$ & $\begin{array}{l}-84.77 \% \\
+16.35 \%\end{array}$ \\
\hline Set V & $C_{\text {rect }}$ & $\begin{array}{l}-50 \% \\
+50 \%\end{array}$ & $\begin{array}{l}1068 \\
1141\end{array}$ & $\begin{array}{l}2744 \\
2647\end{array}$ & $\begin{array}{l}105 \\
127\end{array}$ & $\begin{array}{l}1 \\
9\end{array}$ & $\begin{array}{r}518.3 \\
532.32\end{array}$ & $\begin{array}{l}0.173 \\
0.995\end{array}$ & $\begin{array}{r}-5.24 \% \\
+1.24 \%\end{array}$ & $\begin{array}{r}+2.39 \% \\
-1.23 \%\end{array}$ & $\begin{array}{l}-2.27 \% \\
+0.38 \%\end{array}$ & $\begin{array}{l}-79.81 \% \\
+15.82 \%\end{array}$ \\
\hline Set VI & $C_{r e p}$ & $\begin{array}{l}-12 \% \\
+12 \%\end{array}$ & $\begin{array}{l}1141 \\
1057\end{array}$ & $\begin{array}{l}2655 \\
2702\end{array}$ & $\begin{array}{l}112 \\
117\end{array}$ & $\begin{array}{l}9 \\
2\end{array}$ & $\begin{array}{l}511.82 \\
543.57\end{array}$ & $\begin{array}{l}0.998 \\
0.315\end{array}$ & $\begin{array}{l}+1.24 \% \\
-6.21 \%\end{array}$ & $\begin{array}{r}-0.93 \% \\
+0.82 \%\end{array}$ & $\begin{array}{r}-3.49 \% \\
+2.50 \%\end{array}$ & $\begin{array}{r}+16.17 \% \\
-63.36 \%\end{array}$ \\
\hline Set VII & $\tau_{\text {insp }}$ & $\begin{array}{l}-50 \% \\
+50 \%\end{array}$ & $\begin{array}{l}1116 \\
1134\end{array}$ & $\begin{array}{l}2651 \\
2670\end{array}$ & $\begin{array}{r}105 \\
91\end{array}$ & $\begin{array}{l}3 \\
7\end{array}$ & $\begin{array}{l}528.61 \\
530.58\end{array}$ & $\begin{array}{l}0.613 \\
0.994\end{array}$ & $\begin{array}{r}-0.98 \% \\
+0.62 \%\end{array}$ & $\begin{array}{l}-1.08 \% \\
-0.37 \%\end{array}$ & $\begin{array}{r}-0.32 \% \\
+0.05 \%\end{array}$ & $\begin{array}{l}-28.62 \% \\
+15.70 \%\end{array}$ \\
\hline Set VIII & MTTR & $\begin{array}{l}-50 \% \\
+50 \%\end{array}$ & $\begin{array}{c}959 \\
1176\end{array}$ & $\begin{array}{c}1559 \\
4011\end{array}$ & $\begin{array}{c}128 \\
113\end{array}$ & $\begin{array}{l}4 \\
7\end{array}$ & $\begin{array}{l}418.92 \\
638.79\end{array}$ & $\begin{array}{l}0.660 \\
0.979\end{array}$ & $\begin{array}{l}-14.9 \% \\
+4.35 \%\end{array}$ & $\begin{array}{r}-41.83 \% \\
+49.66 \%\end{array}$ & $\begin{array}{l}-21.00 \% \\
+20.45 \%\end{array}$ & $\begin{array}{l}-23.16 \% \\
+13.97 \%\end{array}$ \\
\hline Set IX & MTTF & $\begin{array}{l}-50 \% \\
+50 \%\end{array}$ & $\begin{array}{l}1118 \\
1209\end{array}$ & $\begin{array}{l}3045 \\
2196\end{array}$ & $\begin{array}{l}102 \\
130\end{array}$ & $\begin{array}{l}6 \\
3\end{array}$ & $\begin{array}{l}532.51 \\
518.65\end{array}$ & $\begin{array}{l}0.966 \\
0.451\end{array}$ & $\begin{array}{l}-0.80 \% \\
+7.27 \%\end{array}$ & $\begin{array}{l}+13.62 \% \\
-18.06 \%\end{array}$ & $\begin{array}{l}+0.42 \% \\
-2.20 \%\end{array}$ & $\begin{array}{l}+12.45 \% \\
-47.50 \%\end{array}$ \\
\hline Set X & $E[p]$ & $\begin{array}{l}-15 \% \\
+15 \%\end{array}$ & $\begin{array}{l}1144 \\
1040\end{array}$ & $\begin{array}{l}2650 \\
2703\end{array}$ & $\begin{array}{l}104 \\
130\end{array}$ & $\begin{array}{r}10 \\
3\end{array}$ & $\begin{array}{l}503.64 \\
550.65\end{array}$ & $\begin{array}{l}1.000 \\
0.329\end{array}$ & $\begin{array}{l}+1.51 \% \\
-7.72 \%\end{array}$ & $\begin{array}{l}-1.12 \% \\
+0.86 \%\end{array}$ & $\begin{array}{r}-5.03 \% \\
+3.83 \%\end{array}$ & $\begin{array}{l}+16.41 \% \\
-61.66 \%\end{array}$ \\
\hline
\end{tabular}


- Variation of proportion of nonconforming items (Set X): A small increase in the average of the proportion of nonconforming items distribution conducts to a significant decrease in the probability of acceptance in order to avoid further replacement cost due the outgoing quality. As more batches will be rejected, the joint production and quality control policies react by reducing the optimal batch size $Q^{*}$ in order to minimize all processing delays (of production, $100 \%$ inspection and rectification) and give more protection to serviceable stock against shortages. The opposite effects are observed when the proportion of defective items decreases.

\section{Conclusion}

The joint production-inventory control policies and statistical quality control techniques have not been sufficiently studied in the literature although they are strongly interrelated. Inman et al. (2003) argued that production systems have a significant impact on quality and they observed a lack of research in the intersection of quality and production system design. This paper contributes to research on the joint design of production and quality control of unreliable batch manufacturing systems, where the production control policy consists of a modified hedging policy and quality control is performed by single sampling plan by attributes. A stochastic mathematical model has been developed to describe the dynamic of production and inventory, to define the system constraints and to calculate the overall incurred cost. Since the optimal solution cannot be obtained analytically due to the nonlinearity and the complexity of the optimization model, we proposed a resolution approach based on integrated enumeration procedure with respect to the acceptance number and a simulation optimization approach to optimize jointly the batch size, the hedging level and the sample size. From an illustrative numerical example and a thorough sensitivity analysis, we showed an important impact of inventory, backlog and transportation costs on the design of the economic sampling plan, and, vice versa, the quality costs have a considerable impact on the economic batch size. Also, we showed a significant impact of the system reliability on the optimal batch size, the optimal safety stock and the economic sampling plan design. An interesting result derived from this study is when the production system becomes more unreliable the outgoing quality increases and consumer satisfaction will be critical towards the quality of final product. Future research can be undertaken to investigate the joint preventive maintenance which improve system reliability, economic production quantity, optimal safety stock and economic sampling plan design. Another area for further research is the consideration of consumer's quality level and consumer's risk constraints in the economic sampling plan design.

\section{References}

Ben-Daya, M., \& Noman, S. (2008). Integrated inventory and inspection policies for stochastic demand. European Journal of Operational Research, 185(1), 159-169.

Ben-Daya, M., Noman, S., \& Hariga, M. (2006). Integrated inventory control and inspection policies with deterministic demand. Computers \& Operations Research, 33(6), 1625-1638.

Besterfield, D. H. (2009). Quality control: Prentice Hall.

Bielecki, T., \& Kumar, P. (1988). Optimality of zero-inventory policies for unreliable manufacturing systems. Operations Research, 36(4), 532-541. 
Bouslah, B., Gharbi, A., Pellerin, R., \& Hajji, A. (2012). Optimal production control policy in unreliable batch processing manufacturing systems with transportation delay. International Journal of Production Research, 51(1), 264-280.

Chakraborty, T., Giri, B., \& Chaudhuri, K. (2009). Production lot sizing with process deterioration and machine breakdown under inspection schedule. Omega, 37(2), 257-271.

Chiu, S. W., Wang, S. L., \& Chiu, Y. S. P. (2007). Determining the optimal run time for EPQ model with scrap, rework, and stochastic breakdowns. European Journal of Operational Research, 180(2), 664-676.

Chung, K. J. (2003). Approximations to production lot sizing with machine breakdowns. Computers \& Operations Research, 30(10), 1499-1507.

Chung, K. J., \& Hou, K. L. (2003). An optimal production run time with imperfect production processes and allowable shortages. Computers \& Operations Research, 30(4), 483-490.

Ercan, S. S., Hassan, M. Z., \& Taulananda, A. (1974). Cost minimizing single sampling plans with AIQL and AOQL constraints. Management Science, 20(7), 1112-1121.

Ferrell, W. G., \& Chhoker, A. (2002). Design of economically optimal acceptance sampling plans with inspection error. Computers \& Operations Research, 29(10), 1283-1300.

Gharbi, A., \& Kenne, J. (2000). Production and preventive maintenance rates control for a manufacturing system: an experimental design approach. International Journal of Production Economics, 65(3), 275-287.

Groenevelt, H., Pintelon, L., \& Seidmann, A. (1992). Production batching with machine breakdowns and safety stocks. Operations Research, 40(5), 959-971.

Groenevelt, H., Pintelon, L., \& Seidmann, A. (1992). Production lot sizing with machine breakdowns. Management Science, 38(1), 104-123.

Hossein Safizadeh, M., \& Thornton, B. M. (1984). Optimization in simulation experiments using response surface methodology. Computers \& Industrial Engineering, 8(1), 11-27.

Inman, R. R., Blumenfeld, D. E., Huang, N., \& Li, J. (2003). Designing production systems for quality: research opportunities from an automotive industry perspective. International Journal of Production Research, 41(9), 1953-1971.

Kim, C. H., \& Hong, Y. (1999). An optimal production run length in deteriorating production processes. International Journal of Production Economics, 58(2), 183-189.

Kim, C. H., Hong, Y., \& Kim, S. Y. (1997). An extended optimal lot sizing model with an unreliable machine. Production Planning \& Control, 8(6), 577-585.

Lavoie, P., Kenné, J. P., \& Gharbi, A. (2007). Production control and combined discrete/continuous simulation modeling in failure-prone transfer lines. International Journal of Production Research, 45(24), 5667-5685.

Lee, H. L., \& Rosenblatt, M. J. (1987). Simultaneous determination of production cycle and inspection schedules in a production systems. Management Science, 33(9),1125-1136.

Li, J., Sava, A., \& Xie, X. (2009). An analytical approach for performance evaluation and optimization of a two-stage production-distribution system. International Journal of Production Research, 47(2), 403-414.

Liao, G. L., Chen, Y. H., \& Sheu, S. H. (2009). Optimal economic production quantity policy for imperfect process with imperfect repair and maintenance. European Journal of Operational Research, 195(2), 348-357. 
Montgomery, D. C. (2008). Design and analysis of experiments. New York: John Wiley \& Sons Inc.

Moskowitz, H., \& Berry, W. L. (1976). A Bayesian algorithm for determining optimal single sample acceptance plans for product attributes. Management Science, 22(11),1238-1250.

Moskowitz, H., Ravindran, A., \& Patton, J. M. (1979). An algorithm for selecting an optimal acceptance plan in quality control and auditing. International Journal of Production Research, 17(6), 581-594.

Mourani, I., Hennequin, S., \& Xie, X. (2008). Simulation-based optimization of a single-stage failure-prone manufacturing system with transportation delay. International Journal of Production Economics, 112(1), 26-36.

Pegden, C. D., Sadowski, R. P., \& Shannon, R. E. (1995). Introduction to simulation using SIMAN. New York: McGraw-Hill.

Peters, M. H., Schneider, H., \& Tang, K. (1988). Joint determination of optimal inventory and quality control policy. Management Science, 34(8), 991-1004.

Porteus, E. L. (1986). Optimal lot sizing, process quality improvement and setup cost reduction. Operations Research, 34(1),137-144.

Rahim, M., \& Ben-Daya, M. (1998). A generalized economic model for joint determination of production run, inspection schedule and control chart design. International Journal of Production Research, 36(1), 277-289.

Ravindran, A., Shin, W. S., Arthur, J. L., \& Moskowitz, H. (1986). Nonlinear integer goal programming models for acceptance sampling. Computers \& Operations Research, 13(5), 611-622.

Rosenblatt, M. J., \& Lee, H. L. (1986). Economic production cycles with imperfect production processes. IIE transactions, $18(1), 48-55$.

Salameh, M., \& Jaber, M. (2000). Economic production quantity model for items with imperfect quality. International Journal of Production Economics, 64(1), 59-64.

Sana, S. S., \& Chaudhuri, K. (2010). An EMQ model in an imperfect production process. International Journal of Systems Science, 41(6), 635-646.

Schilling, E. G., \& Neubauer, D. V. (2009). Acceptance sampling in quality control. Boca Raton : Chapman \& Hall/CRC.

Wetherill, G., \& Chiu, W. (1975). A review of acceptance sampling schemes with emphasis on the economic aspect. International Statistical Review/Revue Internationale de Statistique, 43(2), 191-210. 